\title{
Veterinary Vaccine Potency Testing: Improvement of the NIH Method
}

\author{
Vitalii Nedosekov*1, Ivan Polupan ${ }^{1}$ and Igor Slivko ${ }^{2}$ \\ ${ }^{1}$ National University of Life and Environmental Sciences of Ukraine, Ukraine
}

${ }^{2}$ State Science Institution National Research Institute of Veterinary Virology and Microbiology of Russian Academy of Agricultural Sciences, Russia

*Corresponding author: Vitalii Nedosekov, National University of Life and Environmental Sciences of Ukraine, Ukraine

\begin{tabular}{|c|c|}
\hline ARTICLE INFO & ABSTRACT \\
\hline Received: 㓞 March 19, 2019 & The article presents a critical analysis of the method for evaluating the activity of NIH \\
\hline Published: March 26, 2019 & rabies vaccines and shows a number of significant drawbacks. A theoretical justification \\
\hline
\end{tabular}

Citation: Vitalii Nedosekov, Ivan Polupan, Igor Slivko. Veterinary Vaccine Potency Testing: Improvement of the NIH Method. Biomed J Sci \& Tech Res 16(3)2019. BJSTR. MS.ID.002850.

\section{Introduction}

A high level of mortality caused by rabies among both humans and animals determines the importance of preventative measures to the development of the infection, where the leading role is taken by vaccines, since a successful outcome depends on the type of the vaccine used and how effective it is $[1,2]$. In this regard, it becomes important to develop and use the quality evaluation of inactivated rabies vaccines. Vaccine immunogenicity is a key factor in judging the effectiveness of vaccines. Efficiency of estimation of the inactivated antirabic vaccines during a long period of time is in the article of ongoing research, discussions and publications [2-5]. The NIH is the method most widely used and recommended by the WHO. This test was developed in the USA in 1953 and is used in unmodified form till this day [5-7].

On the one hand, this method is used by nearly all production and control laboratories in the all countries $[5,6,8]$, it also enables to define a protective effect of the drug on experimental animals and has a positive effect on rabies immunization, since immunological response depends on the potency of rabies vaccines to some extent. The problems associated with determining the activity of the test vaccines using $\mathrm{NIH}$, is discussed at many meetings of the WHO $[2,5,7]$. Since as the control strain of infection with the test formulation recommended NIH strain CVS, a vaccine produce from viruses, nonstrain Pasteur, under the control mice infection, may be less active than expected $[2,5]$. In addition, test conditions for the control NIH vaccines differ from the conditions of the target animals vaccinated in practice, even the same drug, leading to significant errors in the assessment of the activity of vaccines $[4,9,10]$. According to these, the aim of our work was a critical analysis and experimental solution to some disadvantages of the test, which is implemented by selecting the NIH isolate for the control infection (challenge), as well as determining the number of vaccinations, the vaccination method and resolving infecting. The aim of the work was to find the optimal NIH test modifications through a single immunization of mice instead of traditional double. This will provide a high level of correlation to the traditional NIH test.

\section{Materials and Methods}

\section{NIH Test}

Immunogenic potency of rabies vaccines has been studied with the use of a classical method by National Institutes of Health (NIH); the results were expressed in IU.

Rabies virus:

a) Six street rabies virus isolates (three representatives of each cluster circulating among animals in Ukraine.:

Cluster 1 (CVS-like isolates) - 10C289 (cat) 0950103 (KRS), 09D121 (dog) 
Cluster 2 (different from CVS isolates) - 10RD387 (raccoon dog), 09C0111 (cattle) and 09F94 (fox). Infectious activity was 2,43,4 lg MLD50/ 0,03 cm3. Pathological material with the diagnosis of rabies were obtained from the collection of the "Center for the study and prevention of rabies in Ukraine» IBM NAAS of Ukraine.

b) Rabies virus, the international reference strain CVS (20\% suspension of infected mouse brain), deposited 25.02.2002., N 205.

\section{Vaccines}

a) Culture rabies inactivated vaccine-Rabizin (The Russian Federation)-a vaccine made from Schyolkovo-51 series number 023;

b) Concentrated purified culture rabies vaccine - KOKAV (The Russian Federation) - a vaccine made from a strain Vnukovo 32 series number 159,

c) Rabies vaccine Verorab (France), series A0388-1 vaccine made from the Pasteur virus strain.

The reason to select these vaccines is that they are made of different origin strains of rabies virus. KOKAV with strain Vnukovo 32 derives from the Street-Alabama-Dufferin strain (SAD) and Verorab vaccine is produced from the original Pasteur Virus strain (PV). In the experiments, we used the industry-standard sample of rabies vaccines immunogenicity, calibrated according to the 4th International Standard, with the immunogenicity index $1.2 \mathrm{IU} / \mathrm{cm}^{3}$.

Trial 1: In this experiment, there was a reduction in the multiplicity of administration of the test material to mice (once instead of twice); In order to complete this task, the vaccine formulations (test and industry standard) were injected once intraperitoneally into white mice, weighing $12-14 \mathrm{~g}, 0.5 \mathrm{~cm}^{3}$, at dilutions of $1: 5,1: 25,1: 125,1: 625.14$ days later it was infected intracerebrally with the fixed WB strain CVS, at a dose of 50100 MLD50/ $0.03 \mathrm{~cm}^{3}$. Over the next 14 days, the animals were observed. Dilution sequences of each vaccine are prepared, and the 50\% endpoints (ED50) for protection against challenge are estimated by the method of Spearman-Karber.

Trial 2: The technique was modified as follows: The test $(3$ KIAV series of strain TC-80) and the reference vaccine were injected at dilutions of $1: 5,1: 25,1: 125,1: 625$ intramuscularly to white mice, weighing 12-14 grams, volume $-0.15 \mathrm{~cm}^{3}$. On day 21 after vaccination, mice were challenged in the subcutaneous tissue of the upper lip with the fixed WB strain "CVS" in a dose of 10-50 $\mathrm{LD}_{50} /$ $0.15 \mathrm{~cm}^{3}$ and observed for 14 days. Then $\mathrm{ED}_{50}$ was calculated and the comparative analysis of the results obtained by the traditional NIH method was conducted.

Trial 3: The evaluation of the protective activity of rabies vaccines was conducted under NIH test, applying double intraperitoneal immunization of white mice, using selected street isolates instead of challenge rabies virus reference strain CVS.

In order to study the protective activity of the above rabies vaccines against genetic variations of street rabies virus isolates, 12 experimental groups consisting of 40 mice each were formed. Six groups of white mice were immunized intraperitoneally (similarly to NIH test) with KOKAV vaccine, and the other six with vaccine Verorab. The mice were administered at $0.5 \mathrm{~cm}^{3}$ vaccine in a dilution of 1: 5, 1:25, 1: 125 and 1: 625. twice with an interval of 7 days. Each of the dilutions was used to vaccinate 10 mice. On the $14^{\text {th }}$ day of the first immunization, intracerebral infection of mice was conducted in a volume of $0.03 \mathrm{~cm}^{3}$, using street infecting isolates instead of rabies virus reference strain CVS for inoculation, in similar doses from 5 to $50 \mathrm{LD}_{50}$. Defining protective activity of rabies vaccines was carried out by calculating 50\% effective dose (ED50).

\section{Results}

\section{Modification of the Method NIH by A Single Immunization}

The results of comparative testing KIAV through the traditional and modified NIH test are shown in Table 1. The data presented in Table 1 show that the rate $\mathrm{ED}_{50}$ with the single immunization by vaccine preparations (NIH modification) was lower than in the case of double immunization (test NIH). Relative immunogenicity of the second series was higher with the single immunization. The potency of the first and third series of vaccines was below the minimum requirements for inactivated rabies vaccines (1 IU). In both methods (modified and traditional NIH), according to the protocol of vaccine trials, both single and double standard samples were used. In order to determine the level of compliance of the results obtained by the modification of the traditional NIH test, a correlation analysis has been made. It is established that the correlation coefficient was 0.99 .

Table 1: The results of comparative testing of rabies vaccines by NIH test with single and double immunization $n=3$.

\begin{tabular}{|c|c|c|c|}
\hline \hline Series number of vaccines & Multiplicity of immunization & Ig ED $_{\mathbf{5 0}}$ & Potency, IU/cm $^{3^{*}}$ \\
\hline \multirow{2}{*}{1} & 2-fold & $2.71 \pm 0.15$ & 1.82 \\
\cline { 2 - 4 } & 1-fold & $1.59 \pm 0.20$ & 0.93 \\
\hline \multirow{2}{*}{2} & 2-fold & $2.12 \pm 0.18$ & 0.47 \\
\cline { 2 - 4 } & 1-fold & $1.43 \pm 0.10$ & 0.64 \\
\cline { 2 - 4 } 3 & 2-fold & $2.63 \pm 0.21$ & 1.52 \\
\cline { 2 - 4 } & 1-fold & $1.57 \pm 0.13$ & 0.89 \\
\cline { 2 - 4 } & 2-fold & $2.45 \pm 0.15$ & 1 \\
\hline \multirow{2}{*}{ Standart } & 1-fold & $1.62 \pm 0.20$ & 1 \\
\hline
\end{tabular}

Note: The average index of three definitions 


\section{Modification of the Method by using NIH Peripheral Test}

The research results are shown in Table 2.

Table 2: The results of the comparative evaluation of KIAV "peripheral" test and NIH test.

\begin{tabular}{|c|c|c|c|c|}
\hline \multirow{2}{*}{$\begin{array}{c}\text { Series Number } \\
\text { of Vaccines }\end{array}$} & \multicolumn{2}{|c|}{ Test NIH* $^{*}$} & \multicolumn{2}{c|}{ "Peripheral" Test } \\
\cline { 2 - 5 } & Ig ED $_{\mathbf{5 0}}$ & $\begin{array}{c}\text { Potency, IU/ } \\
\mathbf{c m}^{3 *}\end{array}$ & Ig ED $_{\mathbf{5 0}}$ & $\begin{array}{c}\text { Potency, IU/ } \\
\mathbf{c m}^{3 *}\end{array}$ \\
\hline 1 series & 2.71 & 1.82 & 2.25 & 1.4 \\
\hline 2 series & 2.12 & 0.47 & 1.87 & 0.58 \\
\hline 3 series & 2.63 & 1.52 & 2.05 & 0.89 \\
\hline Standart & 2.45 & 1 & 2.1 & 1 \\
\hline
\end{tabular}

Note: * the average index of three definitions.

\section{Modification of the Method by using NIH Street Isolate Rabies Virus}

The research results are shown in Table 3. The results presented in Table 3 show that the effective dose (ED50) of rabies vaccine Verorab in all the experiments was higher than KOKAV vaccine, due to its higher immunogenic potency (7.7 IU / dose compared to the immunogenicity of the vaccine KOKAV-3 8 IU / dose). The effective dose (ED50) of the vaccine KOKAV during infecting mice with street rabies virus isolates of CVS-like genetic variant was $0,44 \pm 0,09$, and during infecting them with isolates belonging to a different genetic CVS-version - 0,31 $\pm 0,07$. Similarly, the effective dose (ED50) of rabies vaccine Verorab was obtained in the experiments of challenge with street isolates rabies virus of a CVS-like genetic variant, which was $0,94 \pm 0,22$, and during infecting with different isolates CVS - 0,67 $\pm 0,17$.

Table 3: The protective activity of rabies vaccines against genetic variations of street rabies virus isolates.

\begin{tabular}{|c|c|c|c|c|c|c|c|c|}
\hline \multirow{3}{*}{ Vaccines } & \multicolumn{8}{|c|}{$\mathbf{E D}_{50}$ During Infection with Street Rabies Virus Isolates } \\
\hline & \multicolumn{3}{|c|}{ CVS-like } & \multirow{2}{*}{$\mathbf{M} \pm \mathbf{m}$} & \multicolumn{3}{|c|}{ Different from CVS } & \multirow{2}{*}{$\mathbf{M} \pm \mathbf{m}$} \\
\hline & $10 C 289$ & 09C0103 & 09D121 & & 10RD387 & $09 C 0111$ & 09F94 & \\
\hline KOKAB & 0.49 & 0.32 & 0.51 & $0.44 \pm 0.09$ & 0.35 & 0.21 & 0.37 & $0.31 \pm 0.07$ \\
\hline Verorab & 1.05 & 0.65 & 1.12 & $0.94 \pm 0.22$ & 0.77 & 0.45 & 0.8 & $0.67 \pm 0.17$ \\
\hline
\end{tabular}

\section{Discussion}

The key to success of rabies control is specific prophylaxis, with the use of highly potency inactivated rabies vaccines. In the representation of our experiments, the modification to NIH test is to be made due to:

a) During the traditional NIH test, which includes double immunization-the second vaccine administration is boosting (shielding), which increases the immune response to vaccines disproportionately to vaccine potency. As a result, the final potency of the drug is accelerated.

b) During the test, there were some inconsistencies regarding the conditions of practical application of a vaccine formulation (intramuscular) and a potential route at bites in the nature (intracerebral do not exist in the nature), as well as conditions of immunogenicity control of rabies vaccines (immunization of mice is made intraperitoneally and allowing infection - intracerebrally). This fact indicates the discrepancy between the delivery of viral antigen through vaccination and its control.

c) For the allowing infecting, the rabies virus reference strain CVS is used. It derives from Pasteur virus, and was defined more than 120 years ago, so it may differ significantly from street isolates circulating in the wild regions of Ukraine.

Considering the above, the traditional method NIH was modified by the use of a single immunization of mice instead of the traditional double. In experiments on mice, a single immunization revealed that a single immunization with $\mathrm{ED}_{50}$ (modification $\mathrm{NIH}$ ) was twice lower, which is quite natural. However, the relative immunogenicity of the comparison of both methods was almost unchanged, since while reducing the absolute potency, there was a proportional decrease in the activity of absolute standard, which is used to calculate the potency of the ME vaccines. In our opinion, this modification eliminates the disadvantages of the NIH test, taking into consideration the analysis of the results, which show that the correlation coefficient between the modified and traditional methods of NIH was 0.99. In the second experiment, there was the use of intramuscular immunization of mice and infection in the subcutaneous tissue of the upper lip (peripheral test). The result shows a high degree of correlation with the NIH test results $(\mathrm{r}=$ 0,90 ). The advantage of this modification is that the method follows the natural route of administration of the vaccine antigen and the penetration of street virus, when infecting animals in the nature.

In the third experiment, the analysis of the results showed that while challenging immunized animals with street rabies virus isolates in the same infecting dose $\left(\operatorname{LD}_{50} 5-50\right)$, the effective dose $\left(\mathrm{ED}_{50}\right)$ of the rabies vaccines was different. It was $29-30 \%$ higher when animals were infected with isolates of CVS-like genetic variant, regardless of the vaccine. The results have proved the protection of rabies vaccine against street rabies virus isolates belonging to cluster I to be more effective, compared to isolates belonging to cluster II of genetic variants of the rabies virus. Despite a small amount of test preparations, the modification of the NIH test has revealed the disadvantages of the test and has provided the solutions to them. Moreover, the analysis of the 
literature proves our point of view and confirms the reliability of the research direction. The use of the challenge for regional strains of rabies virus will enable to determine the immunogenic potency of inactivated rabies vaccines used in Ukraine with a certain level of accuracy. Thus, this is the demonstration of the theoretical and experimental possibility of replacing the traditional NIH test by the proposed modification, which has a theoretical basis and may be used in practice after large-scale testing [11-15].

\section{Acknowledgement}

The author is grateful to Mr Kurinnov V, (VNIIVViM, Russia), Ivanov M. (IVM, Ukraine) for valuable discussion of this work and for careful technical support.

\section{References}

1. Barth R, Diderrich G, Weinmann E (1988) NIH-test, a problematic method for testing potency of inactivated rabies vaccine. Vaccine $6(4)$ 369-377.

2. WHO (2005) Expert Consultation on Rabies Technical Report Series 931121.

3. Turner GS (1974) Some observations related to the validity of potency tests for rabies vaccine. Symp Ser Immunobiol 21: 324.

4. Aubert MF, Andral L, Blancou J (1981) Controle d’activite des vaccins antirabiques inactives. Etude critique du test des NIH par un modele experimental dit `Test peripherique. J Biol Stand 9(1): 35-43.

5. Vrzal V, Cupera Z, Chumela J, Zatloukal L (1990) Hodnoceni ucinnosti vyvijene vakciny proti vztekline tkanove inaktivovane NIH testem. Veter Med 6: 373-379.

ISSN: 2574-1241

DOI: 10.26717/BJSTR.2019.16.002850

Vitalii Nedosekov. Biomed J Sci \& Tech Res

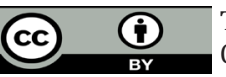

This work is licensed under Creative Commons Attribution 4.0 License

Submission Link: https://biomedres.us/submit-manuscript.php
6. Wilbur LA, Aubert MFA (1996) The NIH test for potency Laboratory techniques in rabies ( $4^{\text {th }}$ Edn.). WHO, pp. 360-368.

7. Germano PML, Silva EV, Silva EV (1990) Evaluation of the efficacy of inactivated rabies vaccines against antigenic variation in mice. Arquiv Biol Tecn 3: 551-560.

8. Crick J, Brown F (1978) Questions concerning the potency of rabies vaccine. Dev Biol Stand 40: 179-182.

9. Wysokinska T (1996) Evaluation of the usefulness of the peripheral test for determination of rabies vaccine potency. Med Dosw Mikrobiol 48(34): 211-213.

10. Bijlenga G (2001) The efficacy of a new single post-exposure treatment of rabies in mice without vaccination. Vet Q 23(4): 187-190.

11. Bijlenga G, Joubert L (1974) Haute pathogenicite pour la souris par voie digestive $d$, un composant viral du vaccin antirabique a virus vivant modifie ERA/BHK Sur la prophylaxie de la rage en France (High pathogenicity for mice of a viral component of the modified-live ERA/ $\mathrm{BHK}$ rabies vaccine administered by the oral route Rabies prophylaxis in France). Bulletin de I, Academie 47: 423-435.

12. Blancou J, Aubert MFA, Cain E (1989) Effect of strain differences on potency testing of rabies vaccines in mice. J Biol Stand 17(3): 259-266.

13. Bruckner L, Palatini M, Ackermann M (1988) Reduction of the number of mice used for potency testing of human and animal rabies vaccines. Experiential 44(10): 853-857.

14. Meslin FX, Kaplan MM, Koprowski H (1996) Laboratory techniques in rabies. World Health Organization, Geneva, pp. 476.

15. Tsetlin EM, Romanova LN (1993) Modifications of the method for controlling the immunogenic activity of rabies vaccines. J Microbiology Epidemiol Immunol 2: 84-88.

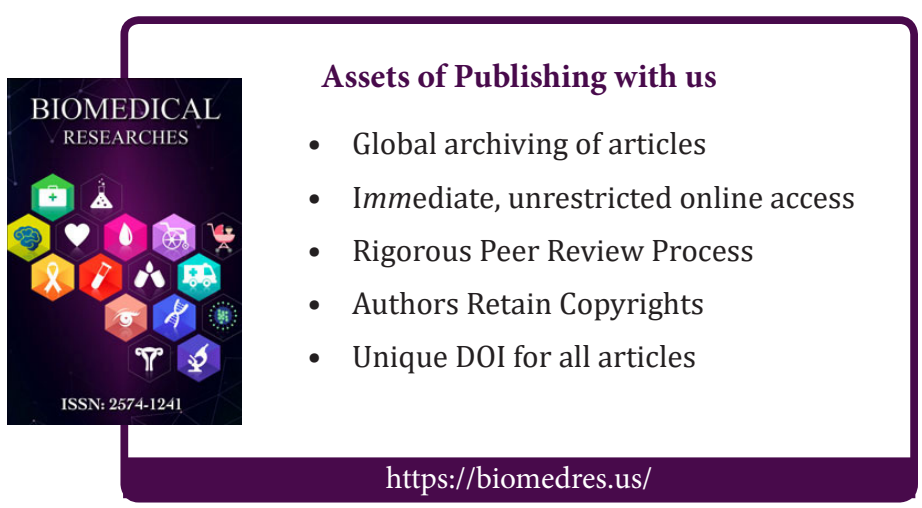

